\title{
O ENSINO DE LEGISLAÇÃO EM CURSOS DE MEDICINA VETERINÁRIA: ANÁLISES CURRICULARES DE UNIVERSIDADES FEDERAIS BRASILEIRAS
}

\author{
Joel Orlando Bevilaqua MARIN ${ }^{i}$ \\ Pauline Vielmo MIRANDA ${ }^{\text {ii }}$
}

\begin{abstract}
RESUMO
O objetivo do artigo é realizar um levantamento dos conteúdos de legislação presentes em disciplinas de projetos pedagógicos de cursos de graduação em Medicina Veterinária. A pesquisa, com abordagem qualitativa, foi elaborada a partir do estudo de vinte projetos pedagógicos vigentes em universidades federais brasileiras. Alguns conteúdos de legislação são apresentados em disciplinas orientadas ao estudo da medicina veterinária legal, bem-estar animal, proteção do meio ambiente e da fauna silvestre, ciências econômicas e sociais, inspeção e sanidade dos produtos de origem animal e medicina veterinária preventiva. Torna-se necessário criar, em todas as universidades brasileiras, uma disciplina específica para o estudo sistemático e abrangente da legislação aplicada à Medicina Veterinária.
\end{abstract}

PALAVRAS-CHAVE: Ensino superior; Legislação veterinária; Medicina Veterinária; Currículo; Projeto pedagógico.

\section{THE TEACHING OF LEGISLATION IN VETERINARY MEDICINE COURSES: CURRICULAR ANALYSIS OF BRAZILIAN FEDERAL UNIVERSITIES}

\begin{abstract}
The purpose od the article is to carry out a survey of the contents of legislation presented in disciplines of pedagogical projects of undergraduate courses in Veterinary Medicine. Research, with a qualitative approach, was elaborated from the study of twenty pedagogical projects current in Brazilian federal universities. Some legislation contents are presented in disciplines oriented to the study of legal veterinary medicine, animal welfare, environmental protection, environment and wildlife, economic and social sciences, inspection and health of animal products and preventive veterinary medicine. It becomes necessary to create, in all Brazilian universities, a specific discipline for the systematic and comprehensive study of legislation applied to Veterinary Medicine.
\end{abstract}

KEYWORDS: Higher education; Veterinary legislation; Veterinary medicine; Curriculum; Pedagogical project.

\footnotetext{
i Pós-Doutorado na École des Hautes Études en Sciences Sociales (2015). Doutorado em Sociologia pela Universidade Estadual Paulista Júlio de Mesquita Filho (2001). Professor Titular da Universidade Federal de Santa Maria. E-mail: bevilaquamarin@gmail.com

ii Mestrado em Educação Profissional e Tecnológica pela Universidade Federal de Santa Maria (2017). Servidora Pública do Governo do Estado do Rio Grande do Sul. E-mail: paulinevielmomiranda@gmail.com
} 


\section{LA ENSEÑANZA DE LEGISLACIÓN EN CURSOS DE MEDICINA VETERINARIA: ANÁLISIS CURRICULARES DE UNIVERSIDADES FEDERALES BRASILEÑAS}

\section{RESUMEN}

El objetivo del artículo es realizar un estudio de levantamiento de los contenidos de legislación, en proyectos pedagógicos de cursos de graduación en Medicina Veterinaria. La investigación, con enfoque cualitativo, fue elaborada a partir del estudio de veinte proyectos pedagógicos, vigentes en universidades federales brasileñas. Algunos contenidos de legislación se presentan en disciplinas orientadas a el estudio de la medicina veterinaria legal, bienestar animal, protección del medio ambiente y de la fauna silvestre, ciencias económicas y sociales, inspección y sanidad de los productos de origen animal, medicina veterinaria preventiva. Es necesario crear, en todas las universidades brasileñas, una disciplina específica para el estudio sistemático y amplio de la legislación aplicada a la Medicina Veterinaria.

PALABRAS CLAVE: Enseñanza superior; Legislación veterinaria; Medicina Veterinaria; Currículum; Proyecto Pedagógico.

\section{INTRODUÇÃO}

O desenvolvimento científico-tecnológico e as práticas na área da Medicina Veterinária guardam estreitas relações com os dispositivos legais. A legislação serve para orientar e disciplinar os diversos campos de atuação, assim como os constantes avanços e as mudanças nas representações sociais sobre os animais, os quais ocorrem em escala nacional e internacional, tornando-se objetos de regulamentação.

Por essa razão, a inclusão de conteúdos de legislação em currículos de cursos de Medicina Veterinária é defendida por organizações com atividades nos âmbitos nacional e internacional. A Câmara de Educação Superior (CES) do Conselho Nacional de Educação (CNE), por meio das Diretrizes Curriculares Nacionais (DCN) para os Cursos de Medicina Veterinária, propugna a inclusão curricular de conteúdos relacionados à legislação. Da mesma forma, o Conselho Federal de Medicina Veterinária (CFMV) tem atuado por meio de resoluções - especialmente do Código de Ética do Médico Veterinário - que orientam os profissionais para o domínio necessário de conhecimentos e para o cumprimento de dispositivos legais que regem o exercício profissional e a vida em sociedade. Por sua vez, a Organização Internacional de Epizootias (OIE) recomenda a inclusão de duas disciplinas com conteúdos relacionados à ética e legislação profissional e à legislação aplicada à medicina veterinária.

No entanto, pouco se conhece sobre o ensino de conteúdos de legislação em cursos de Medicina Veterinária nas instituições brasileiras. Mais desconhecidas ainda são as metodologias de ensino-aprendizagem de tais conteúdos, especialmente em um curso que tende 
a valorizar os conhecimentos técnicos em detrimento dos conhecimentos socioeconômicos, jurídicos e ambientais, os quais também estão relacionados ao exercício da profissão de médicoveterinário. Para contribuir com o entendimento dessa problemática, o objetivo deste artigo é realizar um levantamento dos conteúdos de ensino de legislação veterinária existentes em projetos pedagógicos (PPs) dos cursos de graduação em Medicina Veterinária de universidades federais brasileiras.

\section{METODOLOGIA}

Este artigo está fundamentado em uma pesquisa documental, com abordagem qualitativa. Essa opção permite a produção de resultados mais abrangentes sobre o objeto de pesquisa, assim como o entendimento mais detalhado do fenômeno estudado, sem a intenção de enumerar ou quantificar os dados levantados. No presente estudo, os documentos analisados foram os PPs disponibilizados nos sites de cursos de Medicina Veterinária de universidades federais brasileiras. Na seleção dos PPs também foi considerada a distribuição por regiões geográficas brasileiras, de maneira a contemplar universidades sediadas nas diferentes regiões do Brasil.

Com base nesses critérios, o corpus documental da pesquisa foi constituído de vinte PPs de universidades federais, disponibilizados nas páginas das instituições no período do segundo semestre de 2017, sendo: 1) Região Sul: Universidade Federal de Pelotas (UFPEL), Universidade Federal de Santa Maria (UFSM), Universidade Federal de Santa Catarina Campus Curitibanos (UFSC), Universidade Federal do Paraná - Campus Palotina (UFPR), Universidade Federal Fronteira Sul - Campus Chapecó (UFFS) e Universidade Federal do Pampa - Campus Uruguaiana (UNIPAMPA); 2) Região Sudeste: Universidade Federal Rural do Rio de Janeiro (UFRRJ), Universidade Federal de Juiz de Fora (UFJF) e Universidade Federal do Vale do Jequitinhonha e Mucuri (UFVJM); 3) Região Centro-Oeste: Universidade Federal de Goiás - Campus Jataí (UFG); Universidade Federal do Mato Grosso (UFMT); 4) Região Nordeste: Universidade Federal da Bahia (UFBA), Universidade Federal do Piauí Campus Bom Jesus (UFPI), Universidade Federal de Campina Grande - Campus Patos (UFCG), Universidade Federal de Alagoas - Campus Arapiraca (UFAL) e Universidade Federal do Vale do São Francisco (UNIVASF); 5) Região Norte: Universidade Federal do Tocantins - Campus Araguaína (UFT), Universidade Federal de Roraima (UFRR), 
Universidade Federal Rural da Amazônia (UFRA) e Universidade Federal de Rondônia Campus Rolim de Moura (UNIR). Os PPs pesquisados foram aprovados, nas diferentes instituições, entre os anos de 2005 e 2017.

Com base no elenco de disciplinas dos currículos, procurou-se inventariar: 1) No título: as disciplinas que continham palavras direito, legislação, legal, forense, ética, bioética e deontologia aplicada à Medicina Veterinária; 2) Na ementa: as disciplinas que apresentavam conteúdos relacionados à legislação aplicada à Medicina Veterinária; 3) Na bibliografia: as disciplinas que referenciavam dispositivos legais, sejam Constituições Federal ou Estaduais, sejam Leis, Decretos, Portarias, Instruções Normativas e Resoluções. Vale frisar que nesse levantamento não foi considerada a disciplina que aborda a ética e a legislação profissional em Medicina Veterinária, pelo entendimento da importância de uma análise aprofundada, em estudo específico.

\section{ENSINO DA LEGISLAÇÃO EM CURSOS DE MEDICINA VETERINÁRIA: DIRETRIZES E RECOMENDAÇÕES}

O PP constituiu-se como um importante instrumento de orientação dos processos de elaboração e organização do trabalho pedagógico das escolas de Medicina Veterinária. Etimologicamente, segundo o Novo dicionário Aurélio da língua portuguesa, o termo Projeto tem origem no latim projectu, que significa "lançado para diante; ideia que se forma de executar ou realizar algo, no futuro; plano, intento, desígnio; empreendimento a ser realizado dentro de determinado esquema: projeto administrativo; projeto educacional" (FERREIRA, 1986, p. 1400).

Acrescenta-se que, para Gadotti (2000, p. 12), o Projeto Pedagógico “é extensão, ampliação, recriação, inovação, do presente já construído e, sendo histórico, pode ser transformado: 'um projeto necessita rever o instituído para, a partir dele, instituir outra coisa. Tornar-se instituinte"”. Dessa forma, percebemos que o PP deve ser construído por todos os envolvidos no processo educativo, assim como deve ser vivenciado em todos os momentos da vida acadêmica, visto que identifica e caracteriza a instituição de ensino.

Por sua vez, o currículo vem como a proposta de organização do trabalho pedagógico da instituição. Gimeno Sacristán (2000) afirma que o currículo compreende, concomitantemente, uma diversidade de conceitos, como as ideias pedagógicas, a estruturação 
de conteúdos e o detalhamento desses conteúdos. Portanto, trata-se de uma maneira de correlacionar, na prática escolar, o conhecimento existente e a forma para a sua concretização. É o início da organização do processo de aprendizagem do aluno que começa a ser constituído. Entretanto, o autor enfatiza que o currículo "expressa interesses e forças que gravitam sobre o sistema educativo em dado momento e os valores dominantes que regem os processos educativos" (GIMENO SACRISTÁN, 2000, p. 16). Demonstra-se, assim, que o currículo prescrito ainda oscila entre interesses políticos e econômicos dominantes no momento de sua criação, fato que, por vezes, cerceia o currículo real.

Para Arroyo (2011, p.13), o currículo "é o núcleo e o espaço central mais estruturante da função da escola, por causa disso, é o território mais cercado, mais normatizado. Mas, também, o mais politizado, inovado e ressignificado". Os autores Menezes e Santiago (2014, p. 55) destacam que é "importante assumir que os sujeitos são agentes da práxis curricular e o conhecimento do ponto de partida das situações reais é essencial para problematizá-las e avançar na construção de um conhecimento crítico que contribua com uma educação comprometida com a democracia”.

A partir dessas conceituações, percebe-se que o processo de elaboração dos PPs tornase um momento ímpar para a participação social da comunidade acadêmica - de modo especial, do corpo docente. Por meio do currículo, a comunidade acadêmica pode planejar e instituir novas concepções e práticas que serão desenvolvidas no futuro, com o propósito de melhorar a qualidade de ensino. É nesse movimento que se ressignifica a escola, havendo superação de práticas tradicionais e reprodutoras que não se bastam para a formação na Medicina Veterinária.

Quanto às organizações internacionais que fazem recomendações aos cursos de Medicina Veterinária, temos a OIE, a Comissão do Codex Alimentarius e a Organização das Nações Unidas para a Educação, a Ciência e a Cultura (UNESCO), que se tornaram, respectivamente, referências para a elaboração e a atualização da legislação relacionada à sanidade dos animais, à inspeção e sanidade dos produtos de origem animal destinados ao consumo humano e ao reconhecimento universal dos direitos dos animais. Os diversos acordos internacionais em defesa do meio ambiente e do desenvolvimento sustentável construíram não apenas novas ideias e valores sobre a relação do homem com a natureza, mas, sobretudo, a necessidade de desenvolver novas práticas na defesa da vida, cujo dever de proteção é responsabilidade de todos os indivíduos, sociedades e Estados-nação. 
No Brasil, o exercício da profissão de médico-veterinário é regulamentado pela Lei n. ${ }^{\circ}$ 5.517, de 23 de outubro de 1968 (BRASIL, 1968). A lei restringe o exercício da Medicina Veterinária aos profissionais portadores de diplomas expedidos por instituições reconhecidas pelo Ministério da Educação e estabelece que o exercício profissional é permitido somente aos portadores de carteira profissional. A referida lei também tem importância na orientação dos conteúdos a serem ministrados nos cursos de graduação, na medida em que define o exercício de atividades de competências privativas (artigo 5. ${ }^{\circ}$ ) do médico-veterinário, bem como outras atividades que podem ser compartilhadas com outras áreas profissionais (artigo 6. ${ }^{\circ}$ ) em virtude de cargos de instituições públicas ou privadas. Se a lei fixa competências laborais, torna-se, consequentemente, orientadora dos conteúdos ministrados durante os cursos de graduação.

O CFMV e os Conselhos Regionais de Medicina Veterinária (CRMV), conforme definição dos artigos $7 .^{\circ}$ e $8 .^{\circ}$ da Lei n. ${ }^{\circ} 5.517 / 1968$, têm por finalidade fiscalizar o exercício profissional, bem como "orientar, supervisionar e disciplinar as atividades relativas à profissão de médico-veterinário em todo o território nacional" (BRASIL, 1968). No cumprimento de suas atribuições, o CFMV elabora diversas resoluções para normatizar o exercício profissional, as quais demandam o domínio de um conjunto de conhecimentos, práticas, habilidades e valores que precisam ser ensinados aos acadêmicos.

Nesse sentido, vale destacar a Resolução n. ${ }^{\circ} 1.138$, de 16 de dezembro de 2016, que aprova o Código de Ética do Médico-Veterinário, na orientação e observância de dispositivos legais que regem o exercício profissional e a vida em sociedade (CFMV, 2016). Em uma leitura atenta, constata-se que o Código de Ética tem sólida fundamentação nos dispositivos legais vigentes no País. Isso pode ser evidenciado desde seus princípios fundamentais, nos direitos e deveres, no comportamento e responsabilidade profissional, na publicidade dos trabalhos de pesquisa e nas relações com os colegas de profissão com os consumidores de serviços, com a justiça, com os animais e com o meio ambiente. Algumas passagens do Código de Ética são explícitas quanto ao dever dos médicos-veterinários em "conhecer a legislação de proteção aos animais, de preservação dos recursos naturais e do desenvolvimento sustentável, da biodiversidade e da melhoria da qualidade de vida" (CFMV, 2016, p. 9). Embora essas normativas sejam destinadas aos profissionais inscritos no CFMV, é ao longo do processo de formação dos futuros médicos-veterinários que os conhecimentos jurídicos e éticos devem ser ensinados. 
O Ministério da Educação também estabelece normas nacionais para o ensino dos cursos de graduação de Medicina Veterinária. Os PPs pesquisados seguem as diretivas da Resolução n. ${ }^{\circ}$ 1, de 18 de fevereiro de 2003, Câmara de Educação Superior do Conselho Nacional de Educação (CNE/CES). Contudo, a promulgação da Resolução n. ${ }^{\circ}$ 3, de 15 de agosto de 2019, pelo CNE/CES implicará, necessariamente, atualização dos currículos dos cursos de Medicina Veterinária no Brasil. O objetivo dessa Resolução é instituir as diretrizes curriculares nacionais do curso de graduação em Medicina Veterinária, as quais devem ser observadas na organização, no desenvolvimento e na avaliação dos PPs nas instituições do Sistema de Educação Superior existentes no Brasil. O perfil do egresso de cursos de graduação em Medicina Veterinária deve ter como objetivo fundamental uma "formação generalista, humanista, crítica e reflexiva, apto a compreender e traduzir as necessidades de indivíduos, grupos sociais e comunidades" com relação às diversas atividades inerentes ao exercício profissional do médico-veterinário (CNE/CES, 2019, p. 1).

Em 2012, pensando nos profissionais recém-formados em cursos de Medicina Veterinária, a OIE publicou as Recomendações sobre as competências mínimas esperadas dos médicos-veterinários recém-formados, a fim de garantir serviços veterinários de qualidade nos países-membros. Em face da identificação de uma elevada variabilidade na educação veterinária nos distintos países-membros, agentes sociais vinculados à OIE designaram uma comissão de experts com o propósito de elaborar recomendações pertinentes ao ensino de Medicina Veterinária que possam ser aplicadas a todos os países dos cinco continentes. A OIE não visa à proposição de um currículo único, uma vez que reconhece a existência das especificidades nacionais e regionais dos países-membros. Em suas recomendações, ela apresenta algumas diretrizes para o desenvolvimento dos PPs nas instituições de educação veterinária, objetivando a formação de estudantes com competências mínimas e avançadas para a atuação profissional de qualidade. Os conteúdos relacionados à legislação veterinária e à ética profissional nos cursos de Medicina Veterinária, especificamente, assumem importância no escopo das recomendações da OIE:

A legislação veterinária constitui um elemento essencial da infraestrutura nacional que permite que as autoridades veterinárias realizem suas principais funções, incluindo a vigilância epidemiológica, detecção precoce e controle de doenças em animais, incluindo zoonoses, a segurança de alimentos de origem animal e a certificação de animais e produtos de sua origem destinados à exportação. Além disso, as instituições de ensino veterinário devem abordar 
o tema de ética e valores para promover normas de conduta irrepreensíveis e manter a integridade da profissão (OIE, 2012, p. 8).

Em 2013, a OIE apresentou o Plano de Estudos Básicos de Formação Veterinária (OIE, 2013), no qual especifica com clareza o elenco de disciplinas oferecidas, os conteúdos, a sequência de oferta e as relações entre elas visando ao desenvolvimento de competências gerais, avançadas e específicas dos profissionais recém-egressos de instituições de ensino nos paísesmembros. No que tange aos conteúdos de legislação, a OIE propõe o oferecimento de duas disciplinas. A primeira, denominada Legislação Veterinária Nacional e Internacional, disponibilizada entre a metade e o fim do curso de graduação, tem como objetivo proporcionar aos estudantes conhecimentos sobre políticas públicas e legislações relacionadas à sanidade animal, às inspeções sanitárias e certificação, à inocuidade dos alimentos, ao bem-estar animal e ao comércio de animais e produtos derivados. A segunda disciplina, sob a denominação de Legislação e Ética Profissional, facultada ao final do curso de graduação, tem como fim propiciar aos estudantes a compreensão e o conhecimento do conjunto de leis e dispositivos legais que regulamentam o exercício da Medicina Veterinária, bem como os códigos de ética que orientam os valores e as condutas profissionais dos médicos-veterinários (OIE, 2013).

Em suma, a OIE recomenda o estudo da legislação veterinária e da legislação e ética profissional nos cursos de graduação de Medicina Veterinária mediante uma integração curricular. Cabe, enfim, conhecer, por meio deste estudo, os conteúdos de legislação mencionados nos PPs de cursos de Medicina Veterinária de universidades federais brasileiras.

\section{RESULTADOS E DISCUSSÕES}

Nesta seção, a partir dos currículos dos PPs pesquisados, propõe-se apresentar e analisar as disciplinas com conteúdos de legislação, seja em suas ementas, objetivos ou bibliografias. As instituições pesquisadas têm sua organização curricular em disciplinas. Para Beane (2003, p. 92), esse tipo de organização aparece, com algumas exceções, nos currículos das instituições educacionais de todo o mundo.

\subsection{Medicina Veterinária Legal}

Conteúdos jurídicos e éticos são encontrados em uma nova especialidade disciplinar denominada Medicina Veterinária Legal, que vem se afirmando em decorrência de demandas 
relacionadas à proteção ambiental, à criminalização de atos cruéis praticados contra os animais, ao seguro agrícola, aos laudos patológicos e toxicológicos e à inspeção de produtos de origem animal. Essa especialidade auxilia os agentes da justiça com a emissão de laudos, pareceres e resultados de exames.

Embora receba diferentes denominações, a disciplina é ofertada na UFSC, UFCG, UFT e UFRA, UFAL, UFJF, UFVJM e UFRR, com o objetivo de estudar aspectos técnicos e jurídicos relacionados à medicina veterinária legal. Ao analisar as ementas, nota-se que o desenvolvimento da disciplina prioriza o conhecimento de instrumentos, técnicas e materiais fornecidos pela perícia médico-veterinária, especialmente para casos de morte, lesão, dopping e compra e venda de animais, auxiliando na obtenção de resultados úteis aos institutos jurídicos. No que se refere aos aspectos jurídicos, são mencionados: "legislação na área de Medicina Veterinária Legal, atuação do profissional em Medicina Veterinária Legal, noções de direito e criminalística" (UFT, UFAL); causa jurídica da morte, estudo de laudos e pareceres médicosveterinários legais, noções de biodireito (UFJF); aspectos legais e técnicos da atuação do médico-veterinário em perícia técnico-científica (UFVJM); e "legislação na área de Medicina Veterinária Legal e legislação e exames de determinação de resíduos de medicamentos em produtos de origem animal" (UFSC).

O aperfeiçoamento dos mecanismos jurídicos sobre proteção do meio ambiente, direitos dos animais e conscientização da sociedade, pela ação dos meios de comunicação, dos representantes das sociedades protetoras dos animais e dos cidadãos comprometidos com as causas dos animais, o aperfeiçoamento dos mecanismos de entendimento sobre novas modalidades de maus-tratos aos animais, levando ao aumento de denúncias públicas de todas as formas de crimes contra os animais e o meio ambiente. Segundo Yoshida (2013, p. 11), tais processos atribuíram ao Estado "a responsabilidade de materializar os vestígios relacionados com os animais, convergindo o respectivo trabalho ao perito criminal com formação em medicina veterinária". Yoshida (2013) acrescenta que ainda é reduzido o número de médicosveterinários atuantes nos quadros de peritos criminais, embora sejam crescentes as demandas nessa especialidade profissional e que as universidades estão instituindo disciplina de Medicina Veterinária Legal. Além dos crimes de maus-tratos aos animais, conforme Maiorka (2016), são crescentes as demandas de perícias médico-veterinárias legais nas áreas de seguros, toxicologia forense, análise de produtos de origem animal, fraudes e disputas judiciais envolvendo animais, com intuito de auxiliar policiais, advogados e juízes na aplicação da justiça. 
Por tais razões, acredita-se na tendência de aumentar o número de instituições que venham a ofertar essa disciplina como uma nova especialidade ou desenvolver conteúdos integrados com outras disciplinas. Outra possibilidade seria o estudo de conteúdos referentes à Medicina Veterinária Legal de forma interdisciplinar, perpassando pelas mais variadas disciplinas já consagradas pela Medicina Veterinária, visto que a Medicina Veterinária Legal exige conhecimentos especializados nas diversas áreas do conhecimento.

\subsection{Legislação de bem-estar animal}

O tema bem-estar animal tem recebido a atenção de profissionais da Medicina Veterinária, o que pode ser evidenciado pela delimitação de uma área disciplinar (BROOM; MOLENTO, 2004; MOLENTO, 2007; 2008), pela fundação da Associação MédicoVeterinária Brasileira de Bem-Estar Animal, pelo aumento da publicação de pesquisas e da realização de eventos científicos. Além disso, representantes de instituições governamentais e não governamentais, consumidores, representantes das sociedades de defesa dos animais e juristas vêm promovendo importantes debates acerca de aspectos técnicos, éticos e legais do bem-estar animal.

Ao longo das décadas, tem crescido o interesse de médicos-veterinários e de outros profissionais em estabelecer definições conceituais e parâmetros técnicos do bem-estar animal (BROOM; MOLENTO, 2004). Esse interesse não se dá apenas a fim de alcançar melhores níveis de produção e produtividade, mas também para atender a demandas fundamentadas em critérios éticos e legais das interações entre os seres humanos e os animais. Para além dos animais de interesse zootécnico, o debate conceitual e técnico do bem-estar animal chega aos denominados animais de companhia (MOLENTO, 2007), silvestres e de cativeiro. Vale frisar que as disciplinas contidas nos PPs estudados priorizam as questões técnicas do bem-estar.

Contudo, a dimensão ética do bem-estar animal tem como propósito central o debate das relações e atitudes dos seres humanos com os animais. O ponto de partida é que os animais têm instintos, sentimentos e natureza biologicamente determinados e, nesse sentido, cabe aos homens o dever de poupá-los de todas as formas de sofrimento e maus-tratos. A postura ética na defesa do bem-estar dos animais fundamenta-se no fato de que os animais devem ser respeitados e protegidos pelos cidadãos, pela sociedade e pelo Estado. 
A dimensão legal faz referência às legislações de promoção e defesa dos direitos dos animais, criminalização de atos contra os animais e ao meio ambiente e punição aos indivíduos e às instituições que, deliberadamente ou não, descumprem as normas de proteção dos direitos e do bem-estar dos animais. Nessa perspectiva, segundo Ackel Filho (2001), “já se pode afirmar que a norma atribui aos animais uma espécie de personificação, que os torna sujeitos de direitos dos quais podem gozar e obter a tutela jurisdicional em caso de violação”.

No Brasil, conforme Dias (2000), Ackel Filho (2001), Castro (2006), Rodrigues (2008) e Chuay (2009), existe um amplo aparato legal que dispõe sobre a defesa dos direitos e do bemestar animal. Além disso, em tramitação no Congresso Nacional, encontram-se diversos projetos de lei com propósitos de atualizar a legislação de bem-estar animal, com destaque para o PL 215/2007, que estabelece o Novo Código Federal de Bem-Estar Animal.

Essa área disciplinar tende a valorizar os princípios e os conhecimentos técnicos sobre comportamento animal e bem-estar animal. No entanto, nas instituições mencionadas, as ementas contemplam o estudo de temas de legislação, ética e bioética relacionados ao direito dos animais, ao uso de animais na experimentação e à proteção dos animais de produção e de companhia, com o objetivo de desenvolver uma atuação profissional bem-sucedida e pautada por princípios científicos, legais e éticos. Por tais razões, embora as disciplinas de PPs tematizem leis de bem-estar, os princípios de bem-estar propugnados por organismos internacionais, pela Constituição Federal, pelo arcabouço jurídico vigente no País e pelos projetos de lei em tramitação não estão devidamente contemplados nos cursos de Medicina Veterinária das universidades federais pesquisadas.

\subsection{Legislação de proteção do meio ambiente e da fauna: um campo multidisciplinar}

Nas diferentes instituições pesquisadas, um conjunto diversificado de disciplinas apresenta conteúdos relacionados às legislações de proteção ambiental e da fauna silvestre. No entanto, apenas duas instituições contêm disciplinas centradas no Direito Ambiental ou nas Legislações Ambientais. Na UFPI, a disciplina Legislação Ambiental tem com objeto exclusivo o estudo de legislações de proteção do meio ambiente, enquanto na UFVJM a disciplina Direito Agrário e Ambiental coaduna duas temáticas consagradas na área do Direito. Afora essas disciplinas com centralidade na área do Direito, diferentes matérias pontuam temas de 
legislação e ética no estudo de questões relativas à proteção do meio ambiente, conforme Quadro 1.

Quadro 1 - Instituições que ofertam disciplinas com legislações ambientais em seus objetivos ou ementas

\begin{tabular}{|c|c|c|}
\hline Instituição & Disciplina & Objetivos/Ementa \\
\hline UFPI & Legislação Ambiental & A legislação ambiental no Brasil \\
\hline UFVJM & $\begin{array}{c}\text { Direito Agrário e } \\
\text { Ambiental }\end{array}$ & $\begin{array}{l}\text { Princípios constitucionais de proteção do meio ambiente e } \\
\text { legislações de proteção do meio ambiente, licenciamento } \\
\text { ambiental, Código Florestal, crimes e infrações ambientais }\end{array}$ \\
\hline \multirow[t]{2}{*}{ UNIR } & Ecologia & Lei $.^{\circ}{ }^{9} 9.795 / 1999$ \\
\hline & Educação Ambiental & Lei n. ${ }^{\circ} 9.795 / 1999$ \\
\hline UNIVASF & Ciências Ambientais & $\begin{array}{l}\text { Legislação ambiental: conceituação, direito ambiental, } \\
\text { política e sistema nacional de meio ambiente; Constituição } \\
\text { Federal; Legislação IBAMA }\end{array}$ \\
\hline UFBA & $\begin{array}{c}\text { Saúde Ambiental e } \\
\text { Cultura }\end{array}$ & $\begin{array}{l}\text { As leis no contexto saúde-meio ambiente e seus papéis na } \\
\text { sustentabilidade das ações humanas e na relação ética com a } \\
\text { natureza }\end{array}$ \\
\hline
\end{tabular}

Fonte: os autores.

A fauna silvestre, em suas interfaces com o meio ambiente, conservação, manejo, criação e sanidade, também se constitui objeto de disciplinas em diversas instituições pesquisadas. Nesse grupo de disciplinas, as questões técnicas parecem centrais nas ementas e nas bibliografias, mas também são contempladas dimensões éticas e legais relativas à fauna silvestre. O panorama das disciplinas e seus respectivos conteúdos de legislação sobre fauna silvestre pode ser visualizado no Quadro 2.

Quadro 2 - Instituições que ofertam disciplinas com legislações sobre fauna silvestre contidos nos objetivos ou ementas

\begin{tabular}{|c|c|c|}
\hline Instituiçãc & Disciplina & Objetivos/Ementa \\
\hline \multirow[t]{2}{*}{ UFPR } & $\begin{array}{l}\text { Manejo de Animais Silvestres } \\
\text { ex situ }\end{array}$ & $\begin{array}{l}\text { Legislação aplicada à criação da fauna em cativeiro, } \\
\text { transporte e comercialização }\end{array}$ \\
\hline & $\begin{array}{c}\text { Clínica Médica e Cirúrgica de } \\
\text { Animais Silvestres }\end{array}$ & Legislação da fauna de cativeiro \\
\hline \multirow[b]{2}{*}{ UFJF } & Conservação e Manejo da Fauna & Legislação; Aplicação da legislação \\
\hline & Biologia da Conservação & $\begin{array}{c}\text { Discutir o papel da Ética Ambiental e sua importância } \\
\text { para a conservação e as sociedades humanas }\end{array}$ \\
\hline UFPI & Criação de Animais Silvestres & Legislação sobre a criação de animais silvestres \\
\hline UFMT & Medicina de Conservação & $\begin{array}{l}\text { Legislação sobre criação de animais silvestres em } \\
\text { cativeiro para fins científicos e comerciais }\end{array}$ \\
\hline UFRRJ & $\begin{array}{c}\text { Conservação de Recursos } \\
\text { Naturais }\end{array}$ & Princípios de política e legislação conservacionista \\
\hline
\end{tabular}


No Brasil, o Direito Ambiental, como disciplina da área jurídica, é recente. Surgiu da problematização da questão ambiental e consolidou-se, principalmente, a partir da promulgação da Constituição Federal de 1988. Para Milaré (2013, p. 255), Direito Ambiental define-se pelo "complexo de princípios e normas coercitivas reguladoras das atividades humanas que, direta ou indiretamente, possam afetar a sanidade do ambiente em sua dimensão global, visando a sustentabilidade para as presentes e futuras gerações". Considerando-se esse conceito, os médicos-veterinários devem refletir sobre como suas atividades impactam, direta ou indiretamente, o meio ambiente e os animais. Além disso, precisam se colocar em constante preocupação com a adoção, o aprimoramento e o desenvolvimento de técnicas e procedimentos alinhados aos princípios do desenvolvimento sustentável.

Não obstante as louváveis iniciativas de incorporação de conhecimentos jurídicos na área do Direito Ambiental nos PPs de pesquisados, seria necessário proporcionar aos estudantes o estudo dos princípios do Direito Ambiental e das legislações ambientais, especialmente aquelas com maior aderência nas áreas de atuação profissional.

\subsection{Legislação de inspeção e sanidade de produtos de origem animal}

De acordo com as DNC dos cursos de Medicina Veterinária, os conteúdos essenciais devem contemplar conhecimentos teóricos e práticos relativos à Inspeção e Tecnologia dos Produtos de Origem Animal a fim de desenvolver habilidades e competências para "executar a inspeção sanitária e tecnológica de produtos de origem animal" (CNE/CES, 2019, p. 3).

As disciplinas relacionadas à Inspeção de Produtos de Origem Animal estão contempladas em todas as universidades pesquisadas, com ofertas a partir do sétimo semestre e uma carga horária que varia entre 51 a 102 horas-aulas. As ementas das disciplinas centralizam o estudo dos aspectos técnicos da inspeção, higiene e sanidade dos produtos de origem animal. Em algumas universidades, a exemplo da UFPEL, a conjugação das dimensões teóricas, práticas e legais é expressa no objetivo geral da disciplina: “fornecer aos alunos informações teóricas e práticas referentes ao abate, manipulação e conservação da carne e seus derivados, bem como a legislação vigente" (UFPEL, 2009, p. 164).

Entretanto, são as bibliografias dessas disciplinas que revelam a importância do estudo de documentos legais. Primordialmente, há atenção ao Regulamento de Inspeção Industrial e Sanitária de Produtos de Origem Animal (RIISPOA), atualmente regido pelo Decreto n. ${ }^{\circ}$ 
9.013/2017. Diversos outros dispositivos legais são mencionados na bibliografia, com destaque para as Instruções Normativas n. ${ }^{\circ}$ 03/2000 e n..$^{\circ}$ 51/2002, às Portarias n. ${ }^{o}$ 711/1995, n. ${ }^{\circ}$ 304/1996, n. ${ }^{\circ}$ 368/1997 e n. ${ }^{\circ}$ 210/1999 e ao Manual genérico de procedimentos para APPCC em indústrias de produtos de origem animal.

$\mathrm{Na}$ análise da área disciplinar de inspeção e sanidade dos produtos de origem animal, nota-se que os PPs pesquisados contemplam documentos legais como decretos e instruções normativas que regulamentam a inspeção industrial e sanitária de produtos de origem animal. Tais documentos são destinados a especificar aspectos técnicos utilizados nesses serviços e são promulgados pelo Ministério da Agricultura, Pecuária e Abastecimento.

No âmbito acadêmico, tal estudo objetiva demonstrar as estreitas relações existentes entre os aspectos técnicos e os documentos legais. Entretanto, não se encontram menções a importantes leis atinentes ao tema, como a Lei n. ${ }^{\circ}$ 1.283/1950, que dispõe sobre a Inspeção Industrial e Sanitária dos Produtos de Origem Animal, a Lei n. ${ }^{\circ}$ 7.889/1989, que reestrutura o sistema de inspeção dos produtos de origem animal, distribuindo atribuições para as esferas federal, estadual e municipal, e a Lei n. ${ }^{\circ}$ 13.680/2018, que estabelece o processo de fiscalização de produtos alimentícios de origem animal produzidos de forma artesanal. O estudo dessas leis proporcionaria aos estudantes um entendimento mais amplo a respeito de questões da inspeção sanitária dos produtos de origem animal.

\subsection{Legislação de Medicina Veterinária Preventiva e Saúde Pública}

Os conhecimentos de Medicina Veterinária Preventiva, Sanidade Animal e Saúde Pública estão contemplados no DCN para Medicina Veterinária. Observa-se que as disciplinas orientadas ao tema da sanidade animal costumam ser fundamentadas nos regulamentos estabelecidos para os Programas Nacionais de Defesa Sanitária Animal, do MAPA, que permitem que o aluno atue na prevenção, no diagnóstico, no tratamento e na notificação de doenças de interesse aos animais de produção. Os documentos visam à organização, à orientação e à execução das políticas públicas instituídas no País para a garantia da sanidade dos rebanhos com finalidade comercial.

A disciplina de Saúde Pública e Saneamento Ambiental, da UFPR, descreve, na lista de bibliografias, o estudo da Lei n. ${ }^{\circ}$ 8.080/1990, que institui o Sistema Único de Saúde (SUS), a Constituição da República Federativa do Brasil de 1988 e o Manual de Saneamento de 2004 do 
Ministério da Saúde. Na UFFS, com o nome de Fundamentos de Saúde Pública, o foco também é o estudo do SUS.

Verifica-se que muitos conteúdos idênticos são vistos em disciplinas intituladas de forma diferente. Entretanto, na construção das disciplinas, são utilizadas normativas e recomendações do País, levando em consideração as doenças de interesse e o desenvolvimento de competências e habilidades contidas no artigo $5 .^{\circ}$ das DNC dos cursos de Medicina Veterinária.

\subsection{Outras disciplinas com conteúdos de legislação}

Nos PPs pesquisados, levantou-se um conjunto de disciplinas orientadas aos estudos relacionados à atuação dos médicos-veterinários que agreguem, em seus objetivos ou ementas, abordagens de questões legais e éticas, conforme Quadro 3.

Quadro 3 - Instituições que ofertam disciplinas sobre questões legislações e éticas em seus objetivos ou ementas

\begin{tabular}{|c|c|c|}
\hline Instituição & Disciplina & Objetivos/Ementa \\
\hline UNIR & Semiologia Veterinária & $\begin{array}{l}\text { Preparar o aluno para realizar técnicas semiológicas } \\
{[\ldots] \text { coleta de materiais com segurança, competência, }} \\
\text { ética e respeito ao paciente e seu proprietário }\end{array}$ \\
\hline UNIPAMPA & Farmacologia Veterinária & $\begin{array}{c}\text { Experimentação em farmacologia, código de ética no } \\
\text { manuseio de animais }\end{array}$ \\
\hline UFPI & $\begin{array}{c}\text { Tecnologia e Controle dos } \\
\text { Produtos Farmacêuticos } \\
\text { Veterinários }\end{array}$ & Legislação sobre produtos farmacêuticos veterinários \\
\hline UFPR & $\begin{array}{l}\text { Eutanásia, Ortotanásia e } \\
\text { Distanásia }\end{array}$ & $\begin{array}{c}\text { Conduta ética e legislação pertinentes à eutanásia, } \\
\text { ortotanásia e distanásia }\end{array}$ \\
\hline UFJF & $\begin{array}{l}\text { Ciência de Animais de } \\
\text { Laboratório }\end{array}$ & Ética na experimentação animal \\
\hline UFT & Bioterismo & Ética e legislação no uso de animais \\
\hline
\end{tabular}

Fonte: os autores.

Em análise mais ampla das disciplinas em tela, constata-se que há uma valorização dos conhecimentos técnicos pertinentes a cada área disciplinar, o que pode ser apreendido tanto na extensão dos tópicos contidos nos objetivos e na ementa quanto na relação das bibliografias recomendadas. A despeito da importância das dimensões técnicas, essas disciplinas propõem debates correlacionados à legislação e aos aspectos éticos. Vale ressaltar que cada área disciplinar apresenta práticas recomendáveis e respectivos aparatos legais de regulamentação, 
daí a abordagem correlacionada de temas técnicos, legislação e ética poder alcançar significados e entendimentos mais abrangentes no processo de ensino e aprendizagem das diferenciadas disciplinas.

\subsection{Legislação em disciplinas das áreas econômicas e sociais}

Estudos de leis que regulamentam a propriedade e o uso da terra e de instrumentos de política agrícola são proporcionados aos estudantes de Medicina Veterinária em algumas universidades federais, conforme o Quadro 4 a seguir:

Quadro 4 - Instituições, disciplinas e legislações com conteúdos de legislação agrária e agrícola apresentados nos objetivos ou ementas

\begin{tabular}{|c|c|c|}
\hline Instituição & Disciplina & Objetivos/Ementa \\
\hline UFPI & $\begin{array}{c}\text { Legislação } \\
\text { Agrícola }\end{array}$ & $\begin{array}{c}\text { Noções sobre direito de propriedade e agrário, propriedade } \\
\text { territorial rural, desapropriação e legislação de posse e contratos } \\
\text { agrários }\end{array}$ \\
\hline UFRRJ & $\begin{array}{c}\text { Legislação } \\
\text { Agrária }\end{array}$ & $\begin{array}{c}\text { Direito. Legislação. Estatuto da Terra. INCRA e a reforma agrária. } \\
\text { A propriedade da terra. Cadastramento e tributação. Contratos } \\
\text { agrários. A CLT e o trabalhador rural. Cooperativismo e crédito } \\
\text { rural. Reflorestamento }\end{array}$ \\
\hline UFSM & $\begin{array}{c}\text { Legislação } \\
\text { Agrária e } \\
\text { Profissional } \\
\text { Veterinária }\end{array}$ & $\begin{array}{c}\text { Conhecer e discutir aspectos referentes a: Estatuto da Terra; Código } \\
\text { Florestal; Estatuto do Trabalhador Rural e políticas associativas e } \\
\text { crédito rural }\end{array}$ \\
\hline UFRA & $\begin{array}{c}\text { Política e } \\
\text { legislação }\end{array}$ & Estudo de leis e de políticas agrárias e agrícolas no Brasil e no \\
mundo
\end{tabular}

Fonte: os autores.

Não se pode ignorar a importância das interfaces da legislação agrária e agrícola com áreas de atuação da Medicina Veterinária. No entanto, dada a extensão desse campo do Direito, considera-se necessária uma avaliação mais detalhada daqueles conteúdos que apresentam maiores implicações no exercício profissional dos médicos-veterinários.

No estudo dos PPs, constatou-se que três instituições oferecem disciplinas nas áreas de Economia, Administração e Extensão Rural, que apresentam estudos de legislações em suas ementas ou objetivos, conforme o Quadro 5: 
Quadro 5 - Instituições com disciplinas nas áreas de legislações, Economia, Administração e Extensão Rural apresentadas nos objetivos ou ementas

\begin{tabular}{|c|c|c|}
\hline Instituição & Disciplina & $\begin{array}{c}\text { Objetivos/Ementa } \\
\end{array}$ \\
\hline UFCG & $\begin{array}{c}\text { Economia e } \\
\text { Administração Rural }\end{array}$ & $\begin{array}{l}\text { Princípios gerais da administração, de legislação comercial } \\
\text { aplicada às empresas agropecuárias e de legislação agrária }\end{array}$ \\
\hline UFPI & $\begin{array}{l}\text { Administração de } \\
\text { Cooperativas } \\
\text { Agropecuárias }\end{array}$ & $\begin{array}{c}\text { Cooperativismo e associativismo: histórico, conceito, } \\
\text { doutrina e legislação }\end{array}$ \\
\hline \multirow[t]{5}{*}{ UFVJM } & $\begin{array}{l}\text { Cooperativismo e } \\
\text { Associativismo }\end{array}$ & $\begin{array}{l}\text { Modalidades e implicações legais e institucionais do } \\
\text { associativismo e do cooperativismo }\end{array}$ \\
\hline & Projetos de Crédito Rural & $\begin{array}{c}\text { Legislação de regulamentação da política agrícola de } \\
\text { crédito rural }\end{array}$ \\
\hline & $\begin{array}{l}\text { Ética e Responsabilidade } \\
\text { Social }\end{array}$ & $\begin{array}{c}\text { Noções de ética; moral versus ética; ética nos negócios e } \\
\text { nas relações de trabalho; ética da convicção e ética da } \\
\text { responsabilidade }\end{array}$ \\
\hline & Avaliações e Perícias & Noções de legislação ambiental e agrária \\
\hline & Extensão Rural & Lei n. ${ }^{\circ} 12.188$, de 11 de janeiro de 2010 \\
\hline
\end{tabular}

Fonte: os autores.

As atividades econômicas e administrativas desenvolvidas por pessoas físicas ou pessoas jurídicas, sejam empresas privadas, públicas, sociedades de economia mistas ou cooperativas, estão regulamentadas por legislações e regras específicas. Outrossim, a política e o programa de assistência técnica e extensão rural vigentes no Brasil estão dispostos por legislação própria. Portanto, embora as especificidades das questões econômicas, administrativas ou educativas extensionistas sejam focos centrais dessas áreas disciplinares, suas interfaces com as dimensões legais podem assumir um caráter complementar na formação dos acadêmicos. Ademais, tal propositura confere um caráter transdisciplinar ao conhecimento jurídico, ampliando as competências nas diversas áreas de atuação profissional na Medicina Veterinária.

Na categoria de disciplinas optativas, alguns cursos de Medicina Veterinária apresentam o estudo sobre direitos humanos, diversidade étnico-raciais e língua brasileira de sinais (Libras). Essas temáticas foram incorporadas a instituições com PPs publicados a partir dos anos de 2009, em virtude de adequações às legislações que afirmam direitos dos cidadãos ou que alteram a Lei de Diretrizes e Bases da Educação Nacional.

Na afirmação de direitos sociais dos cidadãos, a disciplina de Direitos e Cidadania, ofertada na UFFS, tem como objetivo permitir que o estudante conheça a categoria cidadania e os conceitos da área do Direito, com o intuito de facilitar a compreensão dos direitos fundamentais que garantem a cidadania e a igualdade pressupostas nos conteúdos jurídico- 
políticos dos cidadãos na modernidade. A disciplina de Ciências Sociais e Humanas, na UNIR, embora tenha centralidade no estudo das correntes teóricas da Sociologia, nos autores clássicos da Sociologia e nos principais objetos de estudo da Sociologia, também propõe a Lei n. ${ }^{\circ}$ 12.986, de 2 de junho de 2014, que transforma o Conselho de Defesa dos Direitos da Pessoa Humana em Conselho Nacional dos Direitos Humanos (CNDH), a fim de estimular debates sobre a "promoção e a defesa dos direitos humanos".

A proposta de disciplina para o estudo das relações étnico-raciais brasileiras a partir de reflexões sobre os aspetos caracterizadores da formação histórica e cultural brasileira e dos povos afro-brasileiros e indígenas está fundamentada na Lei n. ${ }^{\circ}$ 11.645, de 10 de março de 2008, que altera a Lei de Diretrizes e Bases da Educação Nacional (Lei n. ${ }^{\circ}$ 9.394/1996), para incluir, no currículo oficial da rede de ensino, a obrigatoriedade da temática "História e Cultura AfroBrasileira e Indígena”. A sugestão também encontra fundamentação na Resolução CNE/CP n. ${ }^{\circ}$ 01, de 17 de junho de 2004, que institui Diretrizes Curriculares Nacionais para a Educação das Relações Étnico-Raciais e para o Ensino de História e Cultura Afro-Brasileira e Africana. Sob tal orientação legal, a disciplina ganha sentido no estudo de diversidades culturais, construídas por meio das singularidades nas línguas, nas religiões, nos símbolos, nas artes, nas literaturas e em outros legados desses povos para formação da identidade nacional.

Por seu turno, a disciplina que tematiza a Libras está embasada na Lei n. ${ }^{\circ} 10.436$, de 24 de abril de 2002, que dispõe sobre a Língua Brasileira de Sinais (Libras) no Decreto n. ${ }^{\circ}$ 5.626/2005, que regulamenta a Lei n. ${ }^{\circ}$ 10.436/2002 e estabelece sobre a Libras, bem como no art. 18 da Lei n. ${ }^{\circ}$ 10.098, de 19 de dezembro de 2000, que fixa normas gerais e critérios básicos para a promoção da acessibilidade das pessoas portadoras de deficiência ou com mobilidade reduzida, e dá outras providências.

Os currículos, por meio dessas disciplinas, demonstram uma intenção de ampliar a compreensão dos direitos fundamentais dos homens, das culturas regionais e nacionais e das formas de comunicação de pessoas com deficiência auditiva, no sentido da afirmação dos direitos humanos, do pluralismo, da diversidade cultural e da inclusão social. Igualmente, podemos encontrar possibilidades que vão além do que está descrito no currículo formal, pois, como afirma Beane (2003, p. 92), o currículo prescrito cria, inadvertidamente, espaço para algum tempo discricionário, uma vez que alguns professores conseguem cumpri-lo com sucesso, restando, ainda, algum tempo disponível. 
Sendo assim, é possível superar a fragmentação da organização curricular - que, por vezes, torna-se simplista - e otimizar a aprendizagem por meio de discussões sobre a prática profissional do médico-veterinário, visto que se busca integrar teoria e prática.

\section{CONCLUSÃO}

Nas vinte universidades federais brasileiras pesquisadas, os currículos dos cursos de Medicina Veterinária ainda não contemplam uma disciplina específica de Legislação aplicada à Medicina Veterinária. Os conteúdos de legislação são ofertados, de maneira dispersa, em algumas disciplinas das instituições pesquisadas. Tais conteúdos são mais bem evidenciados em disciplinas relacionadas à medicina veterinária legal, ao bem-estar animal, à proteção do meio ambiente e da fauna silvestre e às dimensões econômicas e sociais.

Em áreas de atuação privativa do médico-veterinário, em alguns currículos pesquisados, constam dispositivos legais em disciplinas destinadas ao estudo da inspeção e sanidade de produtos de origem animal e da medicina veterinária preventiva. Essas disciplinas tendem a estudar documentos legais que dispõem sobre critérios técnicos e operacionais, sem menções explícitas nos objetivos, nas ementas ou na bibliografia sobre o estudo dos princípios constitucionais, as leis federais e as possíveis leis estudais que regulamentam essas questões. Em algumas instituições, as disciplinas de semiologia veterinária, farmacologia veterinária, tecnologia e controle de produtos farmacêuticos de uso veterinário, práticas hospitalares em pequenos animais, criação de animais de laboratório e eutanásia preveem o estudo de dispositivos legais.

Se partirmos do princípio de que as Recomendações da OIE são relevantes para a formação das competências e habilidades dos futuros médicos-veterinários, torna-se necessária a proposição da disciplina de Legislação Veterinária com caráter obrigatório e carga horária em torno de 30 horas para proporcionar uma visão ampla de conteúdos relacionados à legislação ambiental, ao bem-estar animal, à experimentação animal, à sanidade animal, à inspeção dos produtos de origem animal e dos produtos de uso veterinário. Nesses conteúdos disciplinares, é preciso considerar o arcabouço legal vigente no País e nos estados da federação, estabelecendo relações com os princípios internacionais e constitucionais que fundamentam essas leis. A essa disciplina deve-se somar outra sobre legislação e ética profissional, com a finalidade de estudar 
as leis que regulamentam o exercício profissional, o código de ética do médico-veterinário e demais resoluções emanadas pelo CFMV.

\section{REFERÊNCIAS}

ACKEL FILHO, Diomar. Direito dos animais. São Paulo: Themis, 2001.

ARROYO, Miguel González. Currículo: território em disputa. Petrópolis: Vozes, 2011.

BEANE, James A. Integração curricular: a essência de uma escola democrática. Currículo Sem Fronteiras, v. 3, n. 2, p. 91-110, jul./dez. 2003.

BRASIL. Lei n. ${ }^{\circ}$ 5.517, de 23 de outubro de 1968. Dispõe sobre o exercício da profissão de médico-veterinário e cria os Conselhos Federal e Regionais de Medicina Veterinária. Diário Oficial da União, Poder Executivo, Brasília, DF, 23 out. 1968. Disponível em: http://www.planalto.gov.br/ccivil_03/LEIS/L5517.htm. Acesso em: 10 maio 2018.

BROOM, Donald Maurice; MOLENTO, Carla Forte Maiolino. Bem-estar animal: conceito e questões relacionadas - revisão. Archives of Veterinary Science, v. 9, n. 2, p. 1-11, 2004.

CASTRO, João Marcos Adede y. Direito dos animais na legislação brasileira. Porto Alegre: Fabris, 2006.

CFMV - Conselho Federal de Medicina Veterinária. Resolução n. ${ }^{\circ}$ 1.138, de 16 de dezembro de 2016. Aprova o Código de Ética do Médico-Veterinário. Diário Oficial da União, Poder Executivo, Brasília, DF, 25 jan. 2017, Seção 1, p. 107-109.

CHUAY, Rafaella. Manifesto pelos direitos dos animais. Rio de Janeiro: Record, 2009.

CNE/CES - Conselho Nacional de Educação/Câmara de Educação Superior. Resolução n. ${ }^{0}$ 3, de 15 de agosto de 2019. Institui Diretrizes Curriculares Nacionais dos Cursos de Graduação em Medicina Veterinária. Brasília: Ministério da Educação, 2019.

DIAS, Edna Cardoso. Tutela jurídica dos animais. Belo Horizonte: Mandamentos, 2000.

FERREIRA, Aurélio Buarque de Holanda. Novo dicionário Aurélio da língua portuguesa. Rio de Janeiro: Nova Fronteira, 1986.

GADOTTI, Moacir. Projeto político-pedagógico da escola: fundamentos para sua realização. In: GADOTTI, Moacir; ROMÃO, José Eustáquio (Orgs.). Autonomia da escola: princípios e propostas. 2. ed. São Paulo: Cortez, 2000. p. 33-41.

GIMENO SACRISTÁN, José. O currículo: uma reflexão sobre a prática. Porto Alegre: Artmed, 2000. 
MAIORKA, Paulo César. Medicina veterinária legal: uma demanda crescente da sociedade. Informativo do CRMV-SP, São Paulo, ano 22, n. 61, fev. 2016.

MENEZES, Marília Gabriela de; SANTIAGO, Maria Eliete. Contribuição do pensamento de Paulo Freire para o paradigma curricular crítico-emancipatório. Revista Pro-Posições [online], v. 25, n. 3, p. 45-62, 2014. Disponível em: http://www.scielo.br/scielo.php?pid=S010373072014000300003\&script=sci_abstract\&tlng=pt. Acesso em: 23 jun. 2018.

MILARÉ, Édis. Direito do ambiente. São Paulo: RT, 2013.

MOLENTO, Carla Forte Maiolino. Bem-estar animal: qual é a novidade? Acta Scientiae Veterinariae, v. 35, n. 2, p. 224-226, 2007.

MOLENTO, Carla Forte Maiolino. Ensino de bem-estar animal nos cursos de medicina veterinária e zootecnia. Ciência Veterinária nos Trópicos, Recife-PE, v. 11, n. 1, p. 6-12, abr. 2008.

OIE - Organização Mundial de Saúde Animal. Plan de estudios básico de formación Veterinaria: directrices de la OIE. Paris: OIE (on-line), 2013.

OIE - Organização Mundial de Saúde Animal. Recomendaciones de la OIE sobre las competências mínimas que se esperan de los veterinarios recién licenciados para garantizar servicios veterinarios nacionales de alta calidad. Paris: OIE; 2012.

RODRIGUES, Daniele Tetü. O direito e os animais: uma abordagem ética, filosófica e normativa. Curitiba: Juruá, 2008.

UFPEL - UNIVERSIDADE FEDERAL DE PELOTAS. Projeto Pedagógico Faculdade de Veterinária. Pelotas, Rio Grande do Sul, 2009. Disponível em:

https://wp.ufpel.edu.br/veterinaria/graduacao/projeto-politico-pedagogico/. Acesso em: 17 jul. 2018.

YOSHIDA, Alberto Soiti. Importância do perito oficial médico veterinário no levantamento de provas nos crimes de maus-tratos aos animais. Orientador: Paulo César Maiorka. 2013. 121 f. Dissertação (Mestrado em Ciências) - Universidade de São Paulo, São Paulo, 2013.

Recebido em: 24/06/2019

Aprovado em: 18/03/2020 